\title{
The analysis of the possibility of using 10 - minute rainfall series to determine the maximum rainfall amount with 5 minutes duration
}

\author{
Bartosz Kaźmierczak ${ }^{1,}{ }^{*}$, Katarzyna Wartalska $^{1}$, Marcin Wdowikowski ${ }^{2}$, and Andrzej \\ Kotowski ${ }^{1}$ \\ ${ }^{1}$ Wrocław University of Science and Technology, Faculty of Environmental Engineering, \\ Plac Grunwaldzki 13, 50-377 Wrocław, Poland \\ ${ }^{2}$ Institute of Meteorology and Water Management - National Research Institute, Podleśna Street 61, \\ 01-673 Warsaw, Poland
}

\begin{abstract}
Modern scientific research in the area of heavy rainfall analysis regarding to the sewerage design indicates the need to develop and use probabilistic rain models. One of the issues that remains to be resolved is the length of the shortest amount of rain to be analyzed. It is commonly believed that the best time is 5 minutes, while the least rain duration measured by the national services is often 10 or even 15 minutes. Main aim of this paper is to present the difference between probabilistic rainfall models results given from rainfall time series including and excluding 5 minutes rainfall duration. Analysis were made for long-time period from 1961-2010 on polish meteorological station Legnica. To develop best fitted to measurement rainfall data probabilistic model 4 probabilistic distributions were used. Results clearly indicates that models including 5 minutes rainfall duration remains more appropriate to use.
\end{abstract}

\section{Introduction}

In both newly designed and existing sewage systems, according to the European standard PN-EN 752:2008, it is recommended to verify the design assumptions by using hydrodynamic simulations. Designers insufficient access to rainfall databases is the main barrier to model safe drainage systems in Poland. The most commonly required at the entrance to hydrodynamic models are storm and heavy rainfall hyetographs with 5 minutes time resolution. The maximum precipitation models (in the form of IDF or DDF curves) are the grounds for the creation of a model precipitation to use in hydrodynamic models [1-8].

In Poland, an access to the precipitation source data is a matter for the Institute of Meteorology and Water Management (IMWM), the owner of the largest number of meteorological stations in the country. The extremely valuable research material on precipitation, due to the number of the stations and the length of the measurement series (often decades), are paper pluviographic strips, on which precipitation were recorded by 2010. It is possible to read information about rainfall height from the paper strips even with

${ }^{*}$ Corresponding author: bartosz.kazmierczak@pwr.edu.pl 
a resolution time of 5 minutes. Many maximum precipitation models have been developed and applied in engineering practice on the basis of this records [9-12].

Since 2007, the IMWM has been recording precipitation by digital rain gauges. Time series are currently recorded with a 10-minute time resolution, which is a matter of concern because in designing and modeling of sewage systems it is needed information about shorter precipitation, lasting 5 minutes [1].

In the paper [13], an attempt has been made to develop two maximum precipitation models for Legnica, with the use of generalized exponential distribution (GED) - considered to be the best probability distribution for analyzed meteorological station [11]. The first model based on rainfall data with durations ranging from 5 minutes to 6 days, while the second model was developed on the basis of rainfall data of durations from 10 minutes to 6 days and the amounts of precipitation with the duration of 5 minutes were extrapolated. The comparison, using relative residual mean square error (RRMSE), between predicted precipitation amounts and measurement data revealed that the first precipitation model accurately maps the measurement results. For rainfall with a duration of 5 minutes, the differences between the predicted and measured precipitation amounts at the level of RRMSE $=2.9 \%$ were noticed. The results of using the second model to determine precipitation heights with a 5 minute duration (parameters extrapolation) were not correlated with the measurement results $($ RRMSE $=41.5 \%$ ) and therefore, the GED distribution is inappropriate for estimating precipitation amounts for the duration of $t=5$ min and it is requested to increase the temporal resolution of recorded rainfall for 5-minute or shorter intervals.

In this paper, the utility of the other, applied in practice, probability distributions was examined, i.e. Fréchet, gamma, log-normal and Weibull distributions [11], in order to analyze the possibility of using 10-minute rainfall series to determine the maximum rainfall amount with 5 minutes duration. The analysis was carried out using archival pluviographs from Legnica from the time span 1961-2010. Distribution parameters were calculated (for rainfall duration from 10 to 8640 minutes) and the model describing the dependence of the amount of rainfall on its duration and specified exceedance probability was subsequently established. Then, precipitation amounts for the 5 minutes duration were computed. The obtained results were compared with the measurement data.

\section{Materials and methods}

The meteorological station of IMWM in Legnica is a part of national measurement and observation network at hydrological and meteorological service. This synoptic station is located on the south-eastern outskirts of the city, at an elevation of $122 \mathrm{~m}$ above the sea level. Fields and wasteland are the main land use in both municipality and rural areas around the station [11]. In this study, the archival pluviographs from this IMWM meteorological station from the time span 1961-2010 were used as a research material.

A selection of data has been done in order to determine the relationship between the amount of rainfall from its duration and probability of exceedance $h(t, p)$. Elaborating archival pluviographs authors limited period of analysis to months from May to October (V-X) [9-11].

From the tested 50-years period top 50 maximum amounts $(h, \mathrm{~mm})$ of rainfall were set apart for each of the following rainfall durations: $t=5,10,20,30,40,50,60,90,120,180$, $360,720,1080,1440,2160,2880,4320,5760,7200$ and 8640 minutes. The isolation has been done on the basis of the Peak-Over-Threshold (POT) method [14-19]. Selected top rainfall heights were listed in descending order. In compliance with following formula:

$$
p(m, N)=\frac{m}{N+1}
$$


where $m$ is the sequence number within a decreasing ordered string of the number of $N$, for each rainfall amount there were assigned the empirical probability of exceedance from $p=0.020$ (for the highest value) to $p=0.980$ (for the lowest value) $[9,10]$. The rainfall heights recorded and selected values of empirical probability assigned to them are shown in Table 1.

Table 1. The amount of rainfall $(h, \mathrm{~mm})$ recorded for selected values of empirical probability $(m=1,5,10,25$ and 50$)$.

\begin{tabular}{|c|c|c|c|c|c|}
\hline \multirow{2}{*}{\begin{tabular}{c}
$\boldsymbol{t}$ min \\
\cline { 2 - 6 }
\end{tabular}} & \multicolumn{6}{|c|}{$\boldsymbol{p 2 0}$} & $\mathbf{0 . 0 9 8}$ & $\mathbf{0 . 1 9 6}$ & $\mathbf{0 . 4 9 0}$ & $\mathbf{0 . 9 8 0}$ \\
\hline 5 & 16.2 & 11.2 & 9.8 & 7.6 & 4.6 \\
\hline 10 & 23.5 & 17.5 & 14.1 & 10.9 & 8.3 \\
\hline 20 & 31.7 & 25.1 & 20.1 & 14.5 & 11.3 \\
\hline 30 & 32.0 & 26.9 & 24.5 & 16.0 & 12.5 \\
\hline 40 & 37.4 & 28.2 & 25.2 & 17.6 & 13.0 \\
\hline 50 & 39.8 & 31.0 & 25.2 & 18.2 & 13.7 \\
\hline 60 & 40.6 & 31.6 & 25.9 & 19.9 & 14.2 \\
\hline 90 & 41.0 & 36.2 & 29.4 & 21.6 & 16.5 \\
\hline 120 & 49.6 & 39.6 & 32.2 & 22.8 & 18.2 \\
\hline 180 & 57.6 & 40.7 & 34.5 & 26.3 & 20.0 \\
\hline
\end{tabular}

\begin{tabular}{|c|c|c|c|c|c|}
\hline \multirow{2}{*}{\begin{tabular}{c}
$\boldsymbol{t}$ min \\
\cline { 2 - 6 }
\end{tabular}} & $\mathbf{0 . 0 2 0}$ & $\mathbf{0 . 0 9 8}$ & $\mathbf{0 . 1 9 6}$ & $\mathbf{0 . 4 9 0}$ & $\mathbf{0 . 9 8 0}$ \\
\hline 360 & 57.7 & 47.2 & 40.9 & 30.6 & 23.9 \\
\hline 720 & 74.9 & 51.8 & 44.6 & 35.8 & 28.6 \\
\hline 1080 & 77.3 & 57.7 & 51.6 & 41.3 & 32.4 \\
\hline 1440 & 77.3 & 66.3 & 57.7 & 46.4 & 35.7 \\
\hline 2160 & 114.8 & 77.3 & 61.1 & 49.4 & 38.7 \\
\hline 2880 & 129.3 & 97.8 & 74.3 & 53.0 & 41.3 \\
\hline 4320 & 143.1 & 97.8 & 77.6 & 57.4 & 41.3 \\
\hline 5760 & 157.0 & 116.0 & 83.9 & 61.9 & 47.1 \\
\hline 7200 & 158.5 & 121.1 & 86.0 & 69.9 & 51.7 \\
\hline 8640 & 167.9 & 132.3 & 91.9 & 71.4 & 53.7 \\
\hline
\end{tabular}

For the description of survey data, the following probability distributions have been used: Fréchet, gamma, log-normal and Weibull distribution. The logarithms of their likelihood functions appear as follows:

$$
\begin{gathered}
\operatorname{Ln} L=\alpha^{n} \beta^{n \alpha} \prod_{i=1}^{n}\left(x_{i}-\gamma\right)^{-(\alpha+1)} \exp \left[-\sum_{i=1}^{n}\left(\frac{\beta}{x_{i}-\gamma}\right)^{\alpha}\right] \\
\ln L=(\alpha-1) \sum_{i=1}^{n} \ln \left(x_{i}-\gamma\right)-n \ln \Gamma(\alpha)-n a \ln \beta-\frac{1}{\beta} \sum_{i=1}^{n}\left(x_{i}-\gamma\right) \\
\ln L=-\sum_{i=1}^{n} \ln \left(x_{i}-\gamma\right)-n \ln \alpha-\frac{n}{2} \ln (2 \pi)-\frac{1}{2 \alpha^{2}} \sum_{i=1}^{n}\left(\ln \left(x_{i}-\gamma\right)-\beta\right)^{2} \\
\ln L=n \ln \alpha-n \alpha \ln \beta+(\alpha-1) \sum_{i=1}^{n} \ln \left(x_{i}-\gamma\right)-\sum_{i=1}^{n}\left(\frac{x_{i}-\gamma}{\beta}\right)^{\alpha}
\end{gathered}
$$

where $\alpha, \beta$ and $\gamma$ are parameters of distributions.

Quantiles of the random variable analyzed distributions takes the form of the following formulas:

$$
\begin{gathered}
h_{p}=\gamma+\beta(-\ln (1-p))^{-\frac{1}{\alpha}} \\
h_{p}=\gamma+\beta t_{p} \\
h_{p}=\gamma+e^{\alpha+\beta t_{p}} \\
h_{p}=\gamma+\beta(-\ln p)^{\frac{1}{\alpha}}
\end{gathered}
$$

The Anderson-Darling test for statistics [20, 21] was used for establishing the coincidence of theoretical distributions with measured data:

$$
A^{2}=-n-\frac{1}{n} \sum_{i=1}^{n}(2 i-1)\left[\ln F\left(X_{i}\right)+\ln \left(1-F\left(X_{n-i+1}\right)\right)\right]
$$

where: $x_{i}-i$-th value in the decreasing ordered random sample, $F(x)$ - cumulative distribution function for the theoretical distribution. The null hypothesis $H_{0}$ (when measurement data were adequate for tested theoretical distribution), was set at a significance level of 0.05 if the $A^{2}$ was less than the critical value $A_{\mathrm{kr}}{ }^{2}$. The alternative hypothesis was taken otherwise. For Fréchet, gamma, log-normal and Weibull distribution 
and for $N=50$ the critical value amounts to respectively: $A_{k r}{ }^{2}=0.757, A_{k r}{ }^{2}=0.762$, $A_{k r}{ }^{2}=0.752$ and $A_{k r}{ }^{2}=0.757$.

For the evaluation of the aptitude of investigated distributions and for describing the survey data, relative residual mean square error (11) was used:

$$
R R M S E=\sqrt{\frac{1}{\mathrm{n}} \sum_{\mathrm{i}=1}^{\mathrm{n}}\left(\frac{\mathrm{h}_{\mathrm{o}, \mathrm{i}}-\mathrm{h}_{\mathrm{p}, \mathrm{i}}}{\mathrm{h}_{\mathrm{p}, \mathrm{i}}}\right)^{2}} \cdot 100 \%
$$

where: $h_{t}$ - the theoretical amount of rainfall $(\mathrm{mm}), h_{m}-$ amount of rainfall from measurements (mm).

\section{Results}

Calculation results of particular parameters of distributions were presented in Tables $2-5$. The parameter estimates were determined by numerical maximization of the log-likelihood functions (2)-(5). The calculations were carried out for each of 20 durations of maximum precipitation amounts analyzed in the paper. All distributions fulfils the compliance criterion $A^{2}$ for each of the 20 analyzed rainfall durations (except log-normal distribution for the duration $t=7200 \mathrm{~min}$ ).

Table 2. Calculation results of parameters of Fréchet distribution.

\begin{tabular}{|c|c|c|c|c|c|}
\hline $\begin{array}{c}\boldsymbol{t}, \\
\mathbf{m i n}\end{array}$ & $\boldsymbol{\alpha}$ & $\boldsymbol{\beta}$ & $\boldsymbol{\gamma}$ & $\boldsymbol{A}^{2}$ & $\begin{array}{r}\text { } \\
\mathbf{z}\end{array}$ \\
\hline 5 & 9.011 & 15.797 & -8.90 & 0.152 & 3.0 \\
\hline 10 & 2.269 & 3.863 & 6.05 & 0.379 & 3.7 \\
\hline 20 & 1.551 & 3.424 & 9.73 & 0.582 & 11.3 \\
\hline 30 & 1.640 & 4.090 & 10.63 & 0.514 & 12.1 \\
\hline 40 & 2.007 & 6.010 & 9.84 & 0.403 & 7.2 \\
\hline 50 & 2.444 & 7.951 & 9.01 & 0.383 & 4.5 \\
\hline 60 & 3.675 & 13.577 & 4.59 & 0.261 & 3.1 \\
\hline 90 & 2.385 & 8.407 & 11.66 & 0.325 & 6.1 \\
\hline 120 & 1.795 & 5.881 & 15.58 & 0.467 & 7.0 \\
\hline 180 & 1.977 & 7.770 & 15.90 & 0.489 & 5.4 \\
\hline
\end{tabular}

\begin{tabular}{|c|c|c|c|c|c|}
\hline $\begin{array}{c}t, \\
\text { min }\end{array}$ & $\alpha$ & $\boldsymbol{\beta}$ & $\gamma$ & $A^{2}$ & క్ \\
\hline 360 & 2.297 & 10.502 & 17.86 & 0.436 & 6.4 \\
\hline 720 & 2.987 & 15.784 & 18.24 & 0.292 & 2.3 \\
\hline 1080 & 2.744 & 15.314 & 22.71 & 0.386 & 3.3 \\
\hline 1440 & 4.479 & 31.384 & 11.68 & 0.323 & 3.0 \\
\hline 2160 & 2.747 & 20.546 & 25.93 & 0.359 & 3.0 \\
\hline 2880 & 1.652 & 14.144 & 35.06 & 0.305 & 7.1 \\
\hline 4320 & 2.266 & 22.305 & 29.40 & 0.232 & 3.3 \\
\hline 5760 & 1.474 & 15.110 & 41.59 & 0.581 & 10.2 \\
\hline 7200 & 1.709 & 18.962 & 41.96 & 0.609 & 7.5 \\
\hline 8640 & 1.829 & 21.802 & 42.79 & 0.399 & 6.3 \\
\hline
\end{tabular}

Table 3. Calculation results of parameters of gamma distribution.

\begin{tabular}{|c|c|c|c|c|c|}
\hline$\underset{\min }{t,}$ & $\alpha$ & $\boldsymbol{\beta}$ & $\gamma$ & $A^{2}$ & $\frac{5}{\Sigma}$ \\
\hline 5 & 2.113 & 1.776 & 4.37 & 0.176 & 3.0 \\
\hline 10 & 0.868 & 4.065 & 8.29 & 0.262 & 2.6 \\
\hline 20 & 0.684 & 7.210 & 11.29 & 0.500 & 3.3 \\
\hline 30 & 0.803 & 6.934 & 12.49 & 0.320 & 4.2 \\
\hline 40 & 0.917 & 6.954 & 12.99 & 0.138 & 2.5 \\
\hline 50 & 0.997 & 6.735 & 13.69 & 0.194 & 2.3 \\
\hline 60 & 1.103 & 6.576 & 14.18 & 0.275 & 2.5 \\
\hline 90 & 0.922 & 8.001 & 16.49 & 0.414 & $\begin{array}{l}3.3 \\
\end{array}$ \\
\hline 120 & 0.955 & 7.894 & 18.19 & 0.404 & 2.9 \\
\hline 180 & 0.885 & 9.458 & 19.99 & 0.177 & 2.4 \\
\hline
\end{tabular}

\begin{tabular}{|c|c|c|c|c|c|}
\hline $\begin{array}{c}\boldsymbol{t}, \\
\text { min }\end{array}$ & $\boldsymbol{\alpha}$ & $\boldsymbol{\beta}$ & $\boldsymbol{\gamma}$ & $\boldsymbol{A}^{2}$ & $\begin{array}{r}\boldsymbol{y} \\
\mathbf{2}\end{array}$ \\
\hline 360 & 0.927 & 10.167 & 23.89 & 0.289 & 3.2 \\
\hline 720 & 0.945 & 11.190 & 28.59 & 0.408 & 2.2 \\
\hline 1080 & 0.969 & 11.555 & 32.39 & 0.249 & 2.2 \\
\hline 1440 & 0.938 & 13.962 & 35.69 & 0.699 & 3.4 \\
\hline 2160 & 0.932 & 16.676 & 38.59 & 0.474 & 3.2 \\
\hline 2880 & 0.831 & 23.882 & 41.29 & 0.163 & 3.3 \\
\hline 4320 & 0.975 & 22.401 & 41.29 & 0.423 & 3.6 \\
\hline 5760 & 0.866 & 28.871 & 47.09 & 0.366 & 3.9 \\
\hline 7200 & 0.666 & 35.982 & 51.69 & 0.410 & 3.8 \\
\hline 8640 & 0.802 & 32.908 & 53.69 & 0.266 & 4.3 \\
\hline
\end{tabular}


Table 4. Calculation results of parameters of log-normal distribution.

\begin{tabular}{|c|c|c|c|c|c|}
\hline$\underset{\text { min }}{t,}$ & $\alpha$ & $\beta$ & $\gamma$ & $A^{2}$ & ș \\
\hline 5 & 0.508 & 1.458 & 3.24 & 0.156 & 2.9 \\
\hline 10 & 0.953 & 0.951 & 7.94 & 0.344 & 3.1 \\
\hline 20 & 1.147 & 1.113 & 11.00 & 0.492 & 7.2 \\
\hline 30 & 1.092 & 1.272 & 12.17 & 0.421 & 8.0 \\
\hline 40 & 0.978 & 1.514 & 12.47 & 0.295 & 5.1 \\
\hline 50 & 0.914 & 1.624 & 13.05 & 0.359 & 3.7 \\
\hline 60 & 0.741 & 1.900 & 12.79 & 0.261 & 2.7 \\
\hline 90 & 0.873 & 1.762 & 15.63 & 0.262 & 4.6 \\
\hline 120 & 0.962 & 1.667 & 17.66 & 0.369 & 4.0 \\
\hline 180 & 1.026 & 1.739 & 19.42 & 0.421 & 4.2 \\
\hline
\end{tabular}

\begin{tabular}{|c|c|c|c|c|c|}
\hline$\underset{\text { min }}{t,}$ & $\alpha$ & $\boldsymbol{\beta}$ & $\gamma$ & $A^{2}$ & 点 \\
\hline 360 & 0.917 & 1.974 & 22.89 & 0.370 & 5.1 \\
\hline 720 & 0.800 & 2.214 & 26.83 & 0.262 & 2.1 \\
\hline 1080 & 0.859 & 2.205 & 30.94 & 0.340 & 2.9 \\
\hline 1440 & 0.694 & 2.579 & 32.30 & 0.303 & 2.8 \\
\hline 2160 & 0.817 & 2.565 & 36.37 & 0.377 & 2.9 \\
\hline 2880 & 1.075 & 2.530 & 40.26 & 0.198 & 4.0 \\
\hline 4320 & 0.870 & 2.819 & 39.09 & 0.207 & 3.0 \\
\hline 5760 & 1.085 & 2.737 & 46.13 & 0.392 & 4.7 \\
\hline 7200 & 1.229 & 2.625 & 50.53 & 0.776 & 7.4 \\
\hline 8640 & 1.076 & 2.828 & 52.13 & 0.375 & 4.8 \\
\hline
\end{tabular}

Table 5. Calculation results of parameters of Weibull distribution.

\begin{tabular}{|c|c|c|c|c|c|}
\hline$\underset{\text { min }}{t,}$ & $\alpha$ & $\beta$ & $\gamma$ & $A^{2}$ & \\
\hline 5 & 1.442 & 3.963 & 4.52 & 0.204 & 3.3 \\
\hline 10 & 0.937 & 3.431 & 8.29 & 0.261 & 2.6 \\
\hline 20 & 0.806 & 4.455 & 11.29 & 0.596 & 3.7 \\
\hline 30 & 0.890 & 5.286 & 12.49 & 0.339 & 4.4 \\
\hline 40 & 0.969 & 6.291 & 12.99 & 0.142 & 2.6 \\
\hline 50 & 1.019 & 6.765 & 13.69 & 0.186 & 2.4 \\
\hline 60 & 1.101 & 7.506 & 14.18 & 0.220 & 2.4 \\
\hline 90 & 0.986 & 7.336 & 16.49 & 0.369 & 3.2 \\
\hline 120 & 0.980 & 7.477 & 18.19 & 0.403 & 3.0 \\
\hline 180 & 0.943 & 8.168 & 19.99 & 0.185 & 2.5 \\
\hline
\end{tabular}

\begin{tabular}{|c|c|c|c|c|c|}
\hline$\underset{\text { min }}{t,}$ & $\alpha$ & $\beta$ & $\gamma$ & $A^{2}$ & 5 \\
\hline 360 & 0.986 & 9.374 & 23.89 & 0.281 & 3.2 \\
\hline 720 & 1.002 & 10.578 & 28.59 & 0.350 & 2.2 \\
\hline 1080 & 1.014 & 11.25 & 32.39 & 0.217 & 2.1 \\
\hline 1440 & 1.028 & 13.216 & 35.69 & 0.565 & 2.6 \\
\hline 2160 & 0.983 & 15.436 & 38.59 & 0.479 & 3.2 \\
\hline 2880 & 0.896 & 18.855 & 41.29 & 0.150 & 3.1 \\
\hline 4320 & 996 & 21.810 & 41.29 & 0.405 & 3.7 \\
\hline 5760 & 0.916 & 24.003 & 47.09 & 0.351 & 3.8 \\
\hline 7200 & 0.787 & 21.279 & 51.69 & 0.527 & 3.9 \\
\hline 8640 & 0.881 & 24.885 & 53.69 & 0.261 & 4.2 \\
\hline
\end{tabular}

Following the equations (6)-(9) and the parameters listed in Tables 2-5, the precipitation amount with any exceedance probability and selected rainfall duration ranging from 5 to 8640 minutes can be calculated. In this respect, it should be noted that the current 10-minute time step of rainfall registration will not allow in the future to estimate parameters for precipitation with the duration of 5 minutes. So these parameters will have to be extrapolated.

The parameters $\beta$ and $\gamma$ have a clearly marked trend. Since there is no dependency trend $\alpha(t)$, the mean value of $\bar{\alpha}=2.312, \bar{\alpha}=0.894, \bar{\alpha}=0.953$ and $\bar{\alpha}=0.954$ was assumed in the calculations (respectively for Fréchet, gamma, log-normal and Weibull distribution).

Based on the calculated distribution parameters there were prepared plots (Fig. 1) showing their dependence on the rainfall duration (from 10 to 8640 minutes).

Finally, a models describing the dependence of the amount of rainfall on its duration and a specified exceedance probability, based on the quantiles (6)-(9), takes the form of:

$$
\begin{gathered}
h_{p}=2.763 t^{0.300}+3.578 t^{0.204}(-\ln (1-p))^{-0.433} \\
h_{p}=5.253 t^{0.256}+1.304 t^{0.355} t_{p}(\alpha, p) \\
h_{p}=4.843 t^{0.261}+e^{0.927 t^{0.127}+0.953 t_{p}(p)} \\
h_{p}=5.253 t^{0.256}+1.879 t^{0.283}(-\ln p)^{1.049}
\end{gathered}
$$



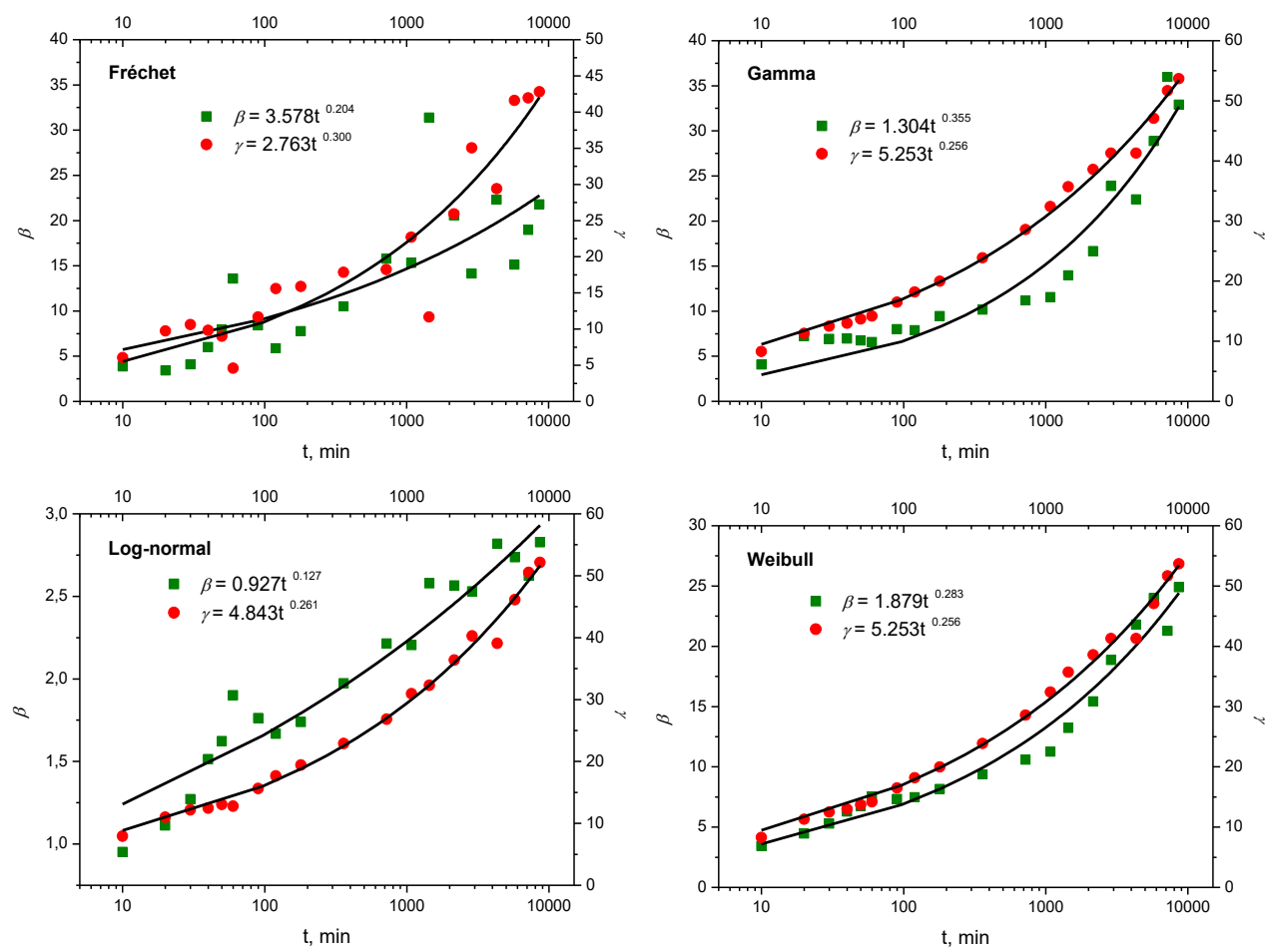

Fig. 1. The dependence of the parameters $\beta$ and $\gamma$ of the rainfall duration.

Based on the obtained formula (12)-(15), precipitation amounts for the 5 min duration were computed. The received results were compared with the measurement data and the precipitation amount calculated using formula (6)-(9) with the parameters from Tables $(2-5)$. The fit quality of the equations for rainfall data from Legnica is shown in the $h-h$ plot (Fig. 2).

Analysis of Figure 2 shows that precipitation amounts calculated from equations (12)-(15) differ significantly from measurement results and from the results obtained from the models (6)-(9) - already similar to measured rainfall data.

There were also calculated relative residual mean square error statistics, covering the entire range of data $(t=5 \mathrm{~min})$. In this case $R_{R M S E}=3.0 \%, 3.0 \%, 2.9 \%$ and $3.3 \%$ for $h$ calculated by (6-9) and $R_{R M S E}=44.3 \%, 30.9 \%, 47.3 \%$ and $37.6 \%$ for $h$ calculated by (12-15). Deviations from the measurements at the level of several dozen percents disqualify analyzed method of determining precipitation amounts with the duration of 5 minutes. 

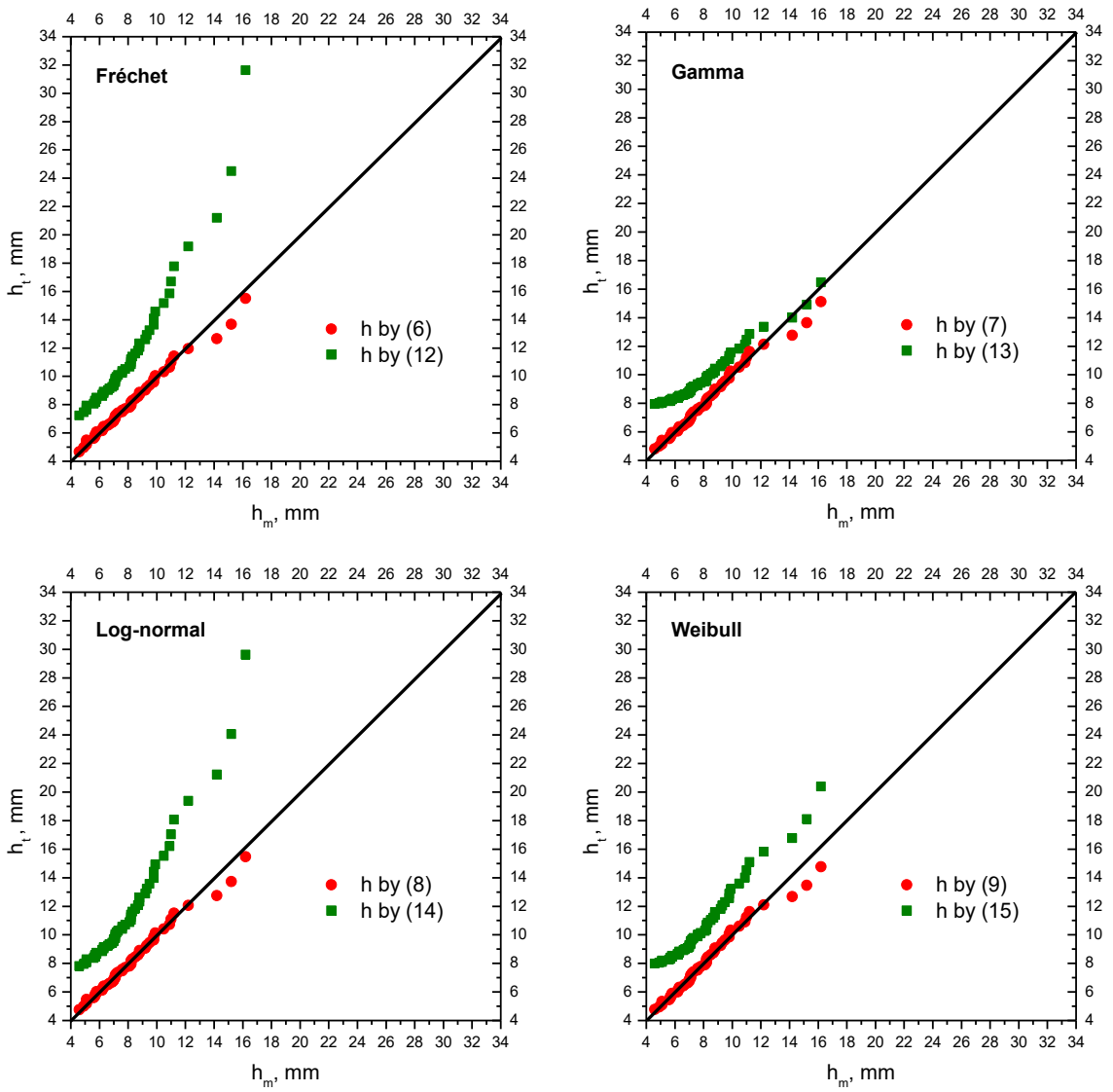

Fig. 2. The $h$ - $h$ plots for the distributions.

\section{Conclusions}

In this paper archival pluviographic records from long term period 1961-2010 were used to develop tow types of probabilistic maximum precipitation models. The area of this research was polish meteorological station in Legnica in Lower Silisia voivodeship. The first group of models were developed on the basis of rainfall data durations from 10 minutes to 6 days. 5 minutes duration precipitation amounts were extrapolated. Models were constructed on four probabilistic distriburions: Fréchet, gamma, log-normal and Weibull. In the second solution only 5 minutes rainfall duration values were computed using all four probability distribution quantiles. Both models were compared with measurement rainfall data using relative residual mean square error. The conducted analysis allowed to draw the following conclusions:

- The maximum precipitation model (6)-(9) with the parameters shown in Table from 2 to 5 thoroughly describes the measurement rainfall data for 5 minutes duration in Table 1 . The $R_{R M S E}$ indicator varies from $2.9 \%$ for log-normal to $3.3 \%$ for Weibull distribution.

- In the case of using models from (12) to (15) to determine precipitation heights with a duration of $t=5 \mathrm{~min}$ (parameters extrapolation) obtained results were not correlated with the measurement results - $R_{R M S E}$ from $30.9 \%$ to $47.3 \%$. Precipitation amounts with a duration of $t=5 \mathrm{~min}$ can be estimated with some approximation based on the 
precipitation heights data for the duration of $t=10 \mathrm{~min}$. The analysis of measurement data indicates that during the period considered, the maximum precipitation with a duration of $t=5 \mathrm{~min}$ represented on average $68 \%$ of maximum rainfall heights with a duration of $t=10 \mathrm{~min}$. However, this estimation should be treated only indicatively, since this variability ranged in the case of the largest 50 precipitations from $55 \%$ to $75 \%$. In order to draw up reliable conclusions, further research in this field involving other measurement stations is needed.

- In the light of the obtained results, it is requested to increase the temporal resolution of recorded by IMWM rainfall for 5-minute or shorter intervals.

Including all above described method should be regarded as inappropriate for estimating precipitation amounts for the duration of $t=5 \mathrm{~min}$. Good quality rainfall model should be based on the 5 minutes rainfall durations that had been measured not extrapolated.

The work was realized within the allocation No. 0401/0006/17 awarded for Faculty of Environmental Engineering Wroclaw University of Science and Technology by Ministry of Science and Higher Education in years 2017-2018.

\section{References}

1. A. Kotowski, The principles of safe dimensioning of sewer systems (Seidel-Przywecki, Warsaw, 2015)

2. E. Burszta-Adamiak, M. Mrowiec, Water Sci Technol 68, 1 (2013)

3. A. Kotowski, K. Wartalska, M. Nowakowska, Ochrona Środowiska 38, 1 (2016)

4. B. Kowalska, D. Kowalski, G. Łagód, M. Widomski, Modelling of Hydraulics and Pollutants Transport in Sewer Systems with Exemplary Calculations in SWMM (Lublin University of Technology, Lublin, 2013)

5. S. Y. Park, K. W. Lee, I. H. Park, S. R. Ha, Desalination 226, 1-3 (2008)

6. T. G. Schmitt, Kommentar zum Arbeitsblatt A 118 Hydraulische Bemessung und Nachweis von Entwässerungssystemen (DWA, Hennef, 2000)

7. T. G. Schmitt, M. Thomas, KA - Wasserwirtschaft, Abwasser, Abfall 47, 1 (2000)

8. D. Słyś, A. Stec, Environment Protection Engineering 38, 4 (2012)

9. A. Kotowski, B. Kaźmierczak, A. Dancewicz, The modeling of precipitations for the dimensioning of sewer systems (Polish Academy of Sciences, Warsaw, 2010)

10. E. Bogdanowicz, J. Stachý, Maximum rainfall in Poland. Design characteristics (The Publishing House of the Institute of Meteorology and Water Management, Warsaw, 1998)

11. B. Kaźmierczak, M. Wdowikowski, Periodica Polytechnica Civil Engineering 60, 2 (2016)

12. R. Suligowski, Maximum credible precipitation at the Kielce Upland (The Jan Kochanowski University, Kielce, 2013)

13. B. Kaźmierczak, K. Wartalska, M. Wdowikowski, E3S Web of Conferences 17, 00038 (2017)

14. W. Jakubowski, Meteorology Hydrology and Water Management 3, 2 (2015)

15. A. Mailhota, S. Lachance-Cloutierb, G. Talbota, A.C. Favrec, J Hydrol 476, 7 (2013)

16. C. Onyutha, Journal of Urban and Environmental Engineering 6, 2 (2012)

17. W. L. Shinyie, N. Ismail, A. A. Jemain, Water Resour Manag 28, 11 (2014)

18. S. Wi, B. J. Valdés, S. Steinschneider, T. W. Kim, Stoch Env Res Risk A 30, 2 (2016) 
19. A. G. Yilmaz, I. Hossain, B. J. C. Perera, Hydrol Earth Syst Sc 18 (2014)

20. R. D’Agostino, M. A. Stephens, Goodness of Fit Techniques (Marcel Dekker, New York, 1986)

21. S. Hongjoon, J. Younghun, J. Changsam, H. Jun-Haeng, Stoch Env Res Risk A 26, 1 (2012) 